\title{
Relato de Experiência: Aplicação das ferramentas de abordagem familiar em um caso de luto
}

\author{
Experience Report: Application of family approach tools in a case of mourning \\ Relato de Experiencia: Aplicación de las herramientas de abordaje familiar en un \\ caso de luto
}

Cynthia Santos Meireles ${ }^{1 *}$, Talles Moreira Falete Mota1 ${ }^{1}$ Anne Raissa Souza Brante ${ }^{1}$.

\begin{abstract}
RESUMO
Objetivo: Relatar o caso e a experiência dos profissionais da Saúde da Família na aplicação das ferramentas de abordagem familiar em um caso de vivência do luto. Metodologia: Trata-se de um relato de caso, descritivo, exploratório, com abordagem qualitativa. As ferramentas aplicadas foram: P.R.A.C.T.I.C.E, FIRO, Genograma, Ciclo de Vida Familiar, Ecomapa e Conferência Familiar. A realização da abordagem familiar proporcionou para os membros da família uma melhor comunicação, esclarecimento de dúvidas sobre o processo de luto e a construção de uma rotina para a paciente índice. Considerações Finais: Reconhecer as necessidades da família é essencial, pois possibilita aos profissionais compreenderem que os processos de adoecimento têm ligação com os eventos da vida, dinâmica familiar, aspectos subjetivos e recursos afetivos e/ou sociais para lidar com adversidades.
\end{abstract}

Palavras-chave: Atenção Primária, Relações Familiares, Luto.

\begin{abstract}
Objective: To report the case and the experience of the professionals of the Family Health in the application of the tools of familiar approach in a case of experience of mourning. Methodology: This is a case report, descriptive, exploratory, with a qualitative approach. The tools applied were: P.R.A.C.T.I.C.E, FIRO, Genograma, Family Life Cycle, Ecomapa and Family Conference. The accomplishment of the family approach provided for the family members better communication, clarification of doubts about the grieving process and the construction of a routine for the index patient. Considerations: Recognizing family needs is essential because it enables professionals to understand that illness processes are linked to life events, family dynamics, subjective aspects, and affective and / or social resources to deal with adversity.
\end{abstract}

Key words: Primary Care, Family Relations, Mourning.

\section{RESUMEN}

Objetivo: Informar el caso y la experiencia de los profesionales de la Salud de la Familia en la aplicación de las herramientas de abordaje familiar en un caso de vivencia del luto. Metodología: Se trata de un relato de caso, descriptivo, exploratorio, con abordaje cualitativo. Las herramientas aplicadas fueron: P.R.A.C.T.I.C.E, FIRO, Genograma, Ciclo de Vida Familiar, Ecomapa y Conferencia Familiar. La realización del enfoque familiar proporcionó a los miembros de la familia una mejor comunicación, aclaración de dudas sobre el proceso de duelo y la construcción de una rutina para la paciente índice. Consideraciones finales: Reconocer las necesidades de la familia es esencial, pues posibilita a los profesionales comprender que los procesos de enfermedad tienen relación con los eventos de la vida, dinámica familiar, aspectos subjetivos y recursos afectivos y / o sociales para lidiar con adversidades.

Palabras clave: Atención Primaria, Relaciones Familiares, Luto.

1 Universidade Estadual de Montes Claros (UNIMONTES), Montes Claros - Minas Gerais.

*E-mail: cynthiameireles@outlook.com

SUBMETIDO EM: 5/2019

ACEITO EM: 6/2019

PUBLICADO EM: 7/2019

REAS/EJCH | Vol. Sup. 26 | e742 | DOI: https://doi.org/10.25248/reas.e742.2019 Página 1 de 7 


\section{INTRODUÇÃO}

A centralização na família é um dos atributos da Atenção Primária em Saúde, sendo necessário o reconhecimento do contexto e dinâmica familiar para bem avaliar e responder às necessidades de saúde dos membros. Para tanto, a equipe de saúde deve ter competência para se comunicar e reconhecer as diversas necessidades da população adscrita em seu território (GIOVANELLA L, MENDONÇA MHM, 2012).

Para capacitar as equipes no cuidado com a família utiliza-se a ferramenta da abordagem familiar: um modelo de reorganização do sistema de saúde - umas das principais estratégias de cuidado realizadas na Atenção Primária. Possibilita à identificação e os limites que existem no contexto familiar e que podem interferir no processo de tratamento do paciente, proporciona vínculo entre profissional e usuário do serviço e facilita a aceitação, investigação e intervenção na família (STARFIELD B, 2002).

Dentre as ferramentas de abordagem familiar na Atenção Primária a Saúde, foram utilizadas para esse estudo: o Problem, Roles, Affect, Communication, Timeoflicycle, Illness, Coping, Ecology - acróstico P.R.A.C.T.I.C.E; Fundamental Interpesonal Relations Orientatios - FIRO; Genograma; Ciclo de Vida Familiar; Ecomapa e a Conferência Familiar.

O P.R.A.C.T.I.C.E, percebe o problema e organiza as informações obtidas com a família, facilitando a sua avaliação, que pode estar relacionada às questões comportamentais, clínicas ou de relacionamento (MOYSÉS SJ, SILVEIRA FAD, 2003).

O FIRO tem por objetivo estudar grupos e sistemas sociais na família. Destina-se a compreender o seu funcionamento, identificando as interações nas categorias: Inclusão, Controle e Intimidade, analisando a família em suas relações de comunicação, afeto e poder (MOYSÉS SJ, SILVEIRA FAD, 2003).

O Genograma é representado pelo desenho gráfico da vida familiar com o objetivo de levantar informações sobre os seus membros e suas relações geracionais, bem como padrões de repetições (MELLO DF, VIERA CS, SIMPIONATO É, 2005).

O Ciclo de Vida Familiar divide a história da família em estágios de desenvolvimento, caracterizados por tarefas específicas e crises evolutivas e/ou eventos previsíveis, que exigem adaptações e ajustamentos de seus membros (MOYSÉS SJ, SILVEIRA FAD, 2003).

O Ecomapa é um instrumento de avaliação dinâmica que contempla as relações entre a família e a comunidade e contribui na análise das estruturas de sustentação disponíveis e na sua utilização pela família (NASCIMENTO LC, et al., 2014). A Conferência familiar possibilita abordar a situação-problema e orientar a família no manejo das dificuldades. Permite que sejam expressos sentimentos e percepções dos membros familiares sobre a situação vivenciada, facilitando a comunicação e a contribuição para resolução do problema (GALRIÇA NI, 2003; LIMA JCM et al., 2008).

O presente trabalho objetiva relatar o caso e a experiência dos profissionais da equipe da Saúde da Família (eSF), na aplicação de ferramentas de abordagem familiar em um caso de vivência do luto. A utilização das ferramentas descritas justifica-se pela importância da avaliação do contexto familiar, da compreensão de sua organização, bem como da sua dinâmica. As ferramentas são válidas na ampliação do foco para além do paciente índice e assim permitem desenvolver intervenções singulares e mais eficazes com a família.

\section{DETALHAMENTO DO CASO}

O trabalho com a família foi desenvolvido por residentes do Programa de Residência Multiprofissional em Saúde da Família da Universidade Estadual de Montes Claros - UNIMONTES em uma eSF do município de Montes Claros/MG, aprovado no Comitê de Ética em Pesquisa da UNIMONTES, sob o parecer de número 572.244 de 27/03/2014. Para resguardar o sigilo foram utilizados nomes fictícios.

Os motivos para a escolha da família foram: 1) ser cadastrada na área de abrangência do território da eSF, 2) procura pelo serviço de saúde de algum membro da família ou indicação do agente comunitário de saúde,

3) paciente apresentar problemas emocionais e de comportamento na família. 
Para coleta de dados foram realizadas quatro visitas domiciliares compartilhadas pelo enfermeiro e psicóloga e quatro atendimentos psicoterápicos individuais. A família foi escolhida após um membro de seu grupo familiar procurar por atendimento psicológico no âmbito da atenção primária.

Aparecida Lima, 45 anos, procurou a eSF e acolhida pelo enfermeiro, relatou que sua filha, Patrícia Lima, 29 anos, havia falecido há poucos dias, deixando filhos e esposo. Com a morte de Patrícia, Afonso, seu genro, começou a morar em sua casa com o propósito de deixar as crianças aos cuidados da bisavó Geralda enquanto trabalhava. Residem na casa: Aparecidas; sua mãe Geralda, 68 anos; seu esposo José Pedro, 47 anos; seu filho Nelson, 20 anos; seu genro Afonso, 30 anos; seu neto Hebert, 4 anos e sua neta Lara, 2 anos. Percebe-se que todos vivem juntos que além do núcleo familiar, outros parentes dividem o espaço conservando bom vínculo. A Figura 1 apresenta o genograma familiar:

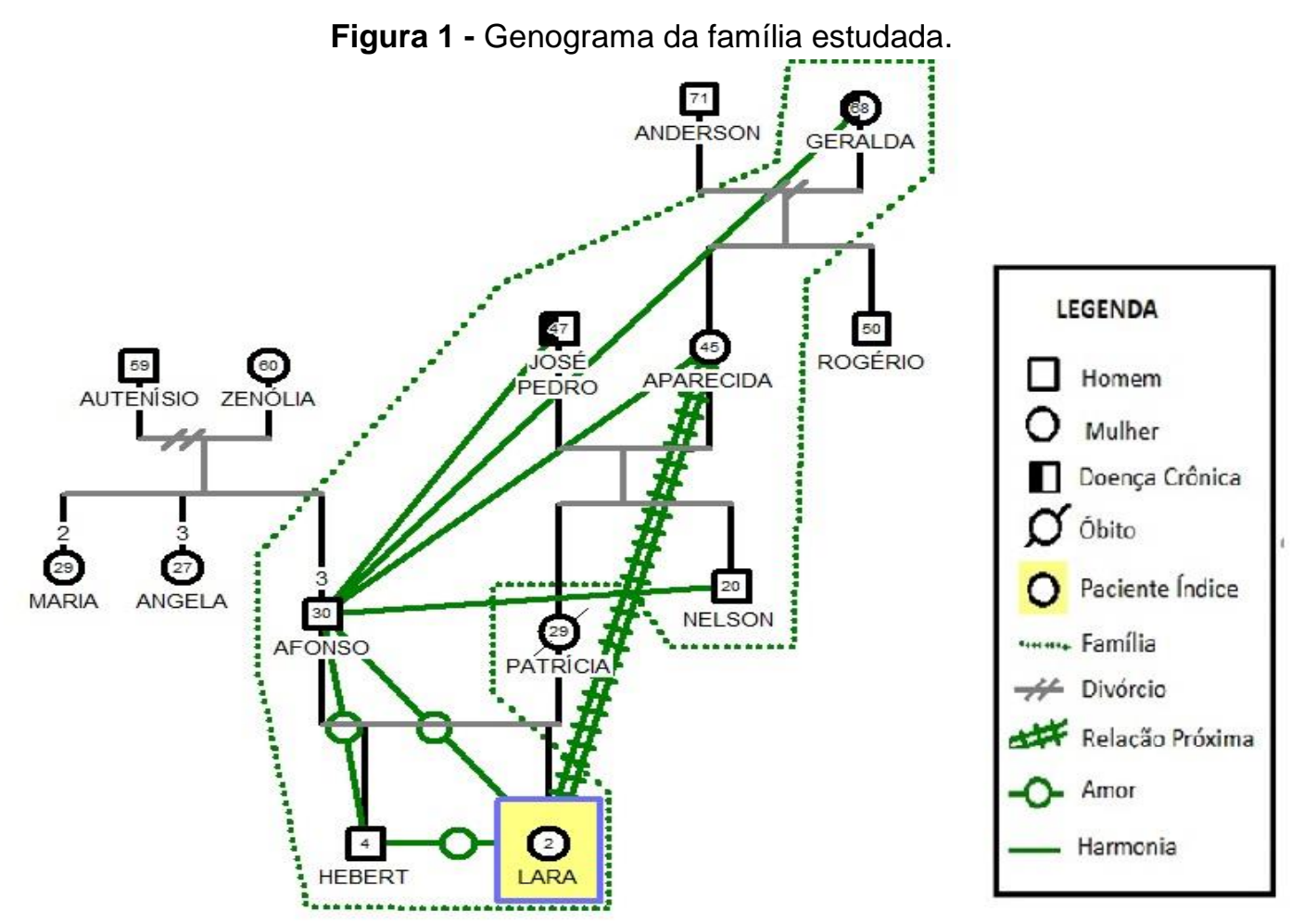

Fonte: Meireles CS, Mota FMT, Brante ARS, 2019.

Na ocasião da abordagem da equipe, a preocupação de Aparecida e Geralda voltava-se para Lara que após o falecimento da mãe apresentou mudanças significativas de comportamento. Demonstrava agitação, ganho de peso e agressividade acentuada com os membros da família, amigos e animal de estimação, regressão nos marcos do desenvolvimento, a saber, enurese diurna/noturna e encoprese diurna.

Outra questão/problema apresentada pela avó foi com relação ao retorno de Afonso para residência dele, juntamente com as crianças. Devido às alterações de comportamento da criança e possível sofrimento psíquico associado, Lara foi escolhida como paciente índice deste relato. Desta maneira, almejou-se um trabalho interdisciplinar com a família, com possíveis ganhos para a paciente índice e seu grupo familiar.

Geralda é portadora das doenças crônicas: hipertensão arterial sistêmica e diabetes mellitus tipo II. Há relato de quadro depressivo há alguns anos. Geralda foi casada com Anderson, mas é divorciada há 20 anos. Dessa relação nasceram dois filhos: Aparecida e Rogério.

Aparecida, casada com José Pedro, trabalha como empregada doméstica. Ele, aposentado, e portador de insuficiência renal crônica, aguarda na fila por um transplante há nove anos. $O$ casal teve dois filhos: Nelson e Patrícia. Nelson, solteiro e realiza o curso técnico em uma escola profissionalizante. 
Patrícia, faleceu após sentir-se mal, há cerca de dois meses. Com quadro de dispneia dirigiu-se aos hospitais municipais, onde foi atendida, medicada e orientada a dar continuidade ao atendimento na Atenção Básica. Após seis dias, sem melhora e diversas tentativas de atendimento sem êxito nos hospitais, foi admitida em uma unidade de pronto atendimento e hospitalizada. Após dois dias de internação, um quadro de parada cardiorrespiratória a levou ao óbito.

Após a morte de Patrícia, Afonso, seu esposo, comerciante, passou a residir, provisoriamente na casa da sogra, pois precisava dos familiares, para auxiliar no cuidar das crianças. Porém, atualmente, demonstrou desejo de retornar para o seu domicílio, incluir as crianças em uma nova escola, próxima de sua casa e passar a contar com a ajuda de sua família no cuidado dos filhos. Em relação à percepção da morte da mãe, Hebert relata que ela "está no céu" e quer que ela "volte rápido" (sic.). Lara acompanhava a mãe em seu trabalho. A menina tem uma relação muito próxima à avó Aparecida e repete a frase de seu irmão de que a mãe "virou uma estrelinha" (sic.). A Figura 1 apresenta o genograma familiar:

$\mathrm{Na}$ avaliação do Ecomapa realizado, os membros têm uma boa relação com os vizinhos. Mantém um bom vínculo com a eSF. Participam ativamente na igreja, vista por eles como forma de interação social e lazer. Geralda participa do grupo de idosos do território. José Pedro realiza acompanhamento no centro de hemodiálise. Aparecida e Afonso trabalham. Dados representados na Figura 2:

Figura 2 - Ecomapa da família estudada.

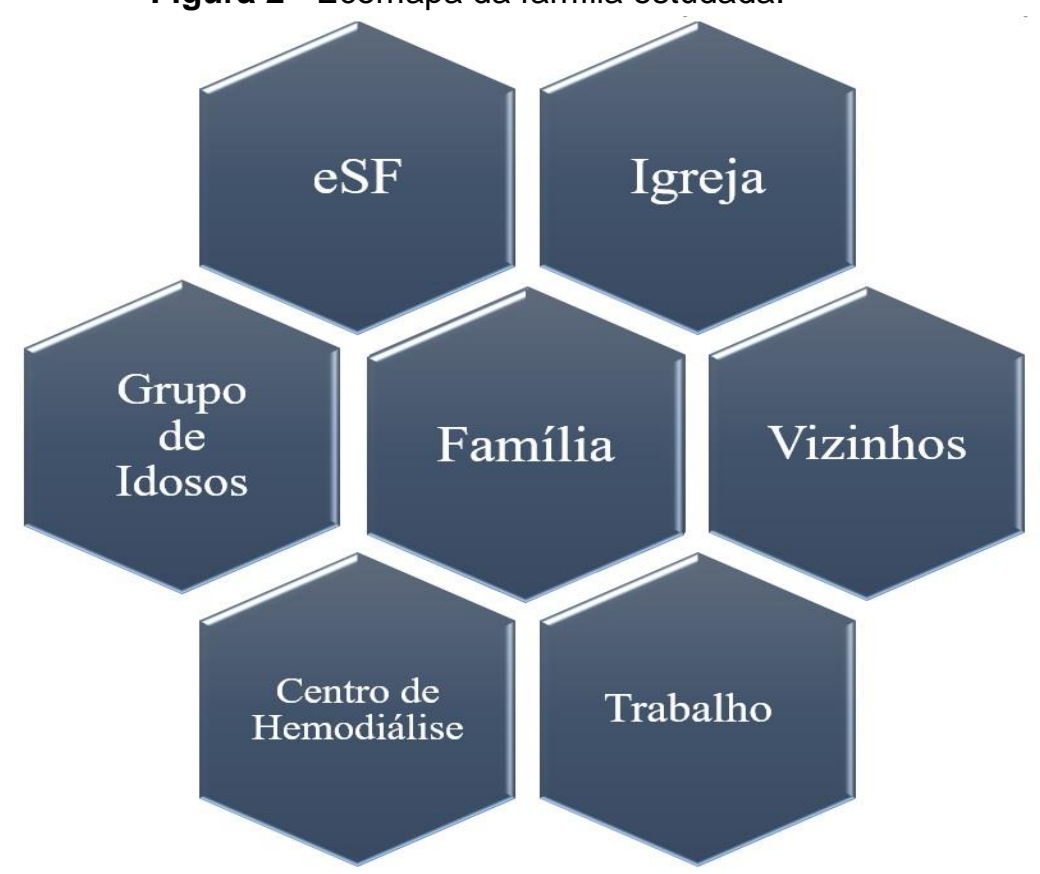

Fonte: Meireles CS, Mota FMT, Brante ARS, 2019.

O P.R.A.C.T.I.C.E permitiu assistir a família de acordo com suas peculiaridades no enfrentamento do problema. A saber:

Problema: mudanças no comportamento de Lara: agressividade, agitação, nervosismo, aumento de peso e retrocesso nos marcos do desenvolvimento e o retorno de Afonso e as crianças para a residência localizada em outro bairro da cidade, distante da casa de Aparecida.

Papéis e Estrutura: Geralda, é aposentada, exerce os cuidados das crianças na ausência do pai Afonso ou Aparecida. Esta exerce a função de chefe de família, mãe, esposa, trabalha em casa ajudando no sustento do lar. José Pedro, aposentado, auxilia nos cuidados dos netos e da casa. Afonso, pai das crianças, trabalha para o sustento dos filhos. Nelson está desempregado, exercendo a função de estudante. 
Afeto: todos os membros do grupo familiar estão sofrendo com o problema por não saberem como manejar o processo de luto da paciente-índice, existindo a preocupação por parte dos cuidadores com relação ao desenvolvimento emocional da paciente, exceto o pai que está em processo de negação do problema.

Comunicação: Aparecida é a porta voz da família. A comunicação é satisfatória entre os membros, mas demonstra estar prejudicada quando a questão se refere ao retorno de Afonso e das crianças para a residência deles em outro bairro.

Tempo do Ciclo de Vida: existem vários tempos no ciclo de vida, são eles: família envelhecendo, filhos pequenos em idade escolar, casal de meia idade, saída da adolescência e a vivência do luto.

Doenças na Família: Geralda possui insuficiência cardíaca em consequência da doença de Chagas. José Pedro possui insuficiência renal crônica, sendo necessária a hemodiálise quatro vezes por semana. O luto vivenciado pela família não é considerado como patológico, pois a morte de Patrícia é muito recente, todavia, tem sido vivido pelos familiares com intenso sofrimento.

Lidando com estresse: A família permaneceu unida para passar pela doença e morte de um dos membros. Apresentam dificuldade no manejo com relação a paciente índice, utilizando de forma ambivalente o castigo para lidar com a agitação e agressividade. Ponto importante a ser destacado é a negação de Afonso quanto às mudanças de comportamento do paciente índice. O trabalho para Aparecida e Afonso é um meio utilizado para suportar a ausência de Patrícia.

Ecologia: A paciente índice possui amigas na vizinhança, frequentemente acompanha o pai em viagens para zona rural, juntamente com a família paterna. Afonso por sua vez, deseja voltar a morar na sua casa. $O$ casal Aparecida e José Pedro não tem momentos de lazer, sendo a igreja o único local de vínculo social saudável. Geralda realiza viagens, danças e artesanato no grupo da comunidade da qual faz parte. A família sempre procura a eSF para os cuidados com a saúde. Residência própria, condição de moradia satisfatória e situação financeira estável.

$\mathrm{Na}$ aplicação da ferramenta FIRO, percebeu-se que a paciente índice é incluída na família, mas nem sempre se submete às regras impostas pelos cuidadores. Na dimensão de controle: as relações de poder são apresentadas por Aparecida (dominante), José Pedro tem pouco controle sobre os demais membros da família. Afonso exerce o controle em relação as crianças e os avós maternos não interferem na tomada de decisões. Quanto à intimidade: todos os entrevistados demonstram boa relação entre si e com os outros familiares. A família tem costume de reunir-se para compartilhar lembranças e momentos de comemorações.

A família estudada caracteriza-se como uma família ampliada. Quatro gerações dividem o mesmo domicílio, apresentado características distintas das várias fases da vida. Uma família com crianças pequenas em idade escolar, envelhecimento e lidando com o luto. No ciclo de vida familiar alguns eventos podem funcionar como estressores, como a vivência do luto, acarretando mudanças nos papéis, o que pode ser constatado após o falecimento de Patrícia.

Durante a conferência familiar, realizada pelo enfermeiro e a psicóloga, estavam presentes: Afonso, Aparecida e José Pedro. Após acolhimento das angústias dos familiares, deu-se início a explicação sobre o atendimento psicoterápico e os possíveis modos de oferta do cuidado à paciente índice.

Foi oportunizado um momento para esclarecer sobre o processo psicoterápico e a vivência do luto na infância. Durante a realização da conferência os familiares informaram sobre a diminuição do nervosismo e agitação da paciente.

A conferência familiar proporcionou aos membros da família uma melhor comunicação, esclarecimento de dúvidas sobre o processo de luto e a construção de uma rotina para a paciente. Possibilitou que Afonso se expressasse sobre a decisão de retornar para a antiga casa, a nova escola dos filhos e a mudança dos cuidadores das crianças, decisão aceita por Aparecida e José Pedro.

Ao final foi acordada a permanência do acompanhamento psicoterápico na eSF, levando em consideração o vínculo estabelecido entre os profissionais e a paciente. 


\section{DISCUSSÃO}

O luto infantil é uma resposta à quebra do vínculo afetivo, com o objetivo de proporcionar a reconstrução de recursos e viabilizar os processos de adaptações ocorridas (BOWLBY J, 2006). O conhecimento sobre o luto tornou-se necessário para compreender as implicações da morte da mãe para a paciente índice, uma vez que a separação se configurou uma potente fonte de sofrimento. Além dos atendimentos psicológicos à criança, houve necessidade de atendimento multiprofissional para a família. Entende-se que a possibilidade do paciente índice elaborar o luto está vinculada ao processo de elaboração do luto pela família e as fantasias inconscientes vivenciadas (GROISMAN M, 2003).

Segundo Torres W (1996), a criança tem dificuldade no processo de elaboração do luto, devido ao psiquismo estar em processo de formação. Em relação aos comportamentos regressivos e agressivos do paciente índice. Bromberg MHPF (2000), ressalta que as reações não patológicas variam entre: reações hostis com familiares e amigos, sentimento de abandono e culpa, retrocesso nos marcos do desenvolvimento neuropsicomotor e choro sem motivo. Assim, os sintomas apresentados pelo paciente índice é algo previsível no processo de vivência do luto, não configurando, neste momento, processo de adoecimento emocional.

A família foi informada que na elaboração do luto é necessário que a criança se expresse para lidar com os diversos sentimentos. Deste modo é importante que a paciente assimile e perceba a realidade através da fala. Nesse contexto, alguém deve exercer a função de continência para os sentimentos, ser capaz de auxiliar a paciente índice suportar a ambivalência emocional provocada pela morte da mãe (FRANCO MHP, MAZORRA L, 2007).

Percebe-se a tentativa de Afonso de reorganizar a vida familiar, manifestada pelo desejo de retornar para o lar de origem com os filhos, sugerindo um início de elaboração do luto. Segundo Moura CM (2006), o processo de elaboração do luto caracteriza-se pela concordância da perda definitiva e pela consequente comprovação do início de uma nova fase da vida. O processo de resolução do luto revela-se organizado quando a morte do cônjuge é aceita e o enlutado expõe sobre a disponibilidade para novos investimentos em sua vida e abre espaço para novas possibilidades ao retomar as atividades que eram desempenhadas antes da morte (FRANCO MHP, MAZORRA L, 2007). Os sintomas apresentados pela criança cessaram após orientação aos cuidadores no manejo com a paciente índice e o acompanhamento psicológico.

O processo de adoecimento possui consistente ligação com os eventos da vida e da dinâmica familiar. Nesse âmbito, a utilização das ferramentas de abordagem familiar proporcionou um conhecimento amplo da família estudada, fazendo surgir fortes vínculos entre família e a eSF, o que favoreceu os resultados alcançados. $O$ trabalho multiprofissional vivenciado neste estudo alavancou novos aprendizados e saberes, suscitando melhores aptidões e maiores competência dos profissionais no manejo do processo de luto.

\section{REFERÊNCIAS}

1. BOWLBY J. Formação e rompimento dos laços afetivos. 4ํㅡㄹ. ed. A. Cabral, Trad. São Paulo: Martins Fontes. 2006 Original publicado em 1972.

2. BROMBERG MHPF. A psicoterapia em situação de perdas e luto. Campinas (SP); 2000.

3. FIGUEIREDO ENA Estratégia Saúde da Família na Atenção Básica do SUS. UNIFESP. UMA-SUS. 2012. V. 5.

4. FRANCO MHP, MAZORRA L. Criança e luto: Vivências fantasmáticas diante da morte do genitor. Estudos de Psicologia, v. 24, 503-511, 2007.

5. GALRIÇA NI. A conferência familiar como instrumento de apoio à família em cuidados paliativos. Revista Portuguesa de Clínica Geral, 2003;19:68-74.

6. GIOVANELLA L, MENDONÇA MHM. Atenção Primária à Saúde: seletiva ou coordenadora dos cuidados? Rio de Janeiro: CEBES, 2012.

7. GROISMAN M. Além do paraíso: perdas e transformações na família. Rio de Janeiro: Núcleo de Pesquisas, 2003.

8. KRÜGER LL, WERLANG BSG. O genograma como recurso no espaço conversacional terapêutico. Avaliação Psicológica, v.7, n.3, p. 415-426, 2008.

9. LIMA JCM, MORAES GLA, AUGUSTO FILHO RF. O uso da conferência familiar na resolução de conflitos de uma família com idosa dependente. Revista Brasileira de Medicina de Família e Comunidade, 2008; 4(14): $129-134$. 
10. MELLO DF, VIERA CS, SIMPIONATO É et al. Genograma e Ecomapa: possibilidades de utilização na estratégia de saúde da família. Rev. Bras. Cresc. Desenv. Hum., v. 15, n. 1, p.78-89, 2005.

11. MOURA CM. Uma avaliação da vivência do luto conforme o modo de morte. Dissertação de (mestrado). Universidade Brasília. Distrito Federal. 2006, $188 \mathrm{f}$.

12. MOYSÉS SJ, SILVEIRA FAD. Os dizeres da boca em Curitiba: boca maldita, boqueirão, bocas saudáveis. Rio de Janeiro: CEBES, 2002. p. 155-60.

13. MOYSÉS ST. et al. Ferramenta de descrição da família e dos seus padrões de relacionamento: genograma: uso em saúde da família. Revista Médica do Paraná, Curitiba, v. 57, n. 1/2, p. 28-33, jan./dez. 1999.

14. NASCIMENTO LC, DANTAS IRO, ANDRADE RD, et al. Genograma e ecomapa: contribuições da enfermagem brasileira. Texto \& Contexto Enfermagem [Internet]. 2014.

15. SANTOS KKF. Ferramentas de abordagem familiar: uma experiência do cuidado multiprofissional no âmbito da estratégia saúde da família. Rev Univ Vale do Rio Verde. 2015; 13(2):377-87.

16. STARFIELD B. Atenção primária: equilíbrio entre necessidades de saúde, serviços e tecnologia. Brasília: Unesco/Ministério da Saúde; 2002.

17. TORRES W. A criança diante da morte. Arquivos Brasileiros de Psicologia. 1996. 48,31-41. 